ning campaign directed as reducing choking in young children using a public education campaign on safe eating.

The project on a tiny budget of $\$ 6000$, developed and distributed a brochure on safe eating practice and nutritional myths. They put significant effort into addressing the misinformation and dangerous practices contained in the popular press, particularly family style magazines, cooking programmes in the media, and in recipes given out by a range of organisations. After great success the program has now been taken up at national level.

IAN SCOTT Kidsafe Australia Level 10, 123 Queen Street, Melbourne, Victoria 3000 Australia

\section{NEWS FROM SAFETY PROGRAMMES}

Editor's note: this section includes a round-up of reports excerpted from newsletters and other publications from community groups and research units received since our last issue. Thanks to all who sent these reports. Please send me any similar material not covered in this or previous issues.

Child Safety Review (Child Accident Prevention Trust, UK)

A lead article in the summer 1996 issue of Child Safety Review describes the results of a survey of parents' concerns. 'Almost half worried more about accidents than any other health hazard' confronting their children, although less than one fifth had had an accurate understanding of the magnitude of the risk. Importantly, a majority thought that more could be done to prevent accidents, including $90^{\prime \prime}$ o who expected more of local councils, government, and television programmes.

\section{Safety Canada}

In a recent issue of this publication of the Canada Safety Council, the lead article focused on drunk drivers. It points out how 'excruciatingly difficult' it is to convict person of impaired driving in Canada because of major loopholes in the law. Between 20 and $40^{\circ}$ " of impaired driving charges are dismissed or reduced because of these loopholes. The drinking and driving sections of the Criminal Code were tightened and severity of penalties increased in December 1985. A subsequent study showed a fall of $47^{\circ}{ }_{0}$ in the rate of persons charged with impaired driving. The study concluded that the law may have failed because the public was not aware of it; it was not fully implemented; it had unexpected countervailing effects; or that the amendments related to severity of sanctions, 'not to the certainty and swiftness of their application'.

\section{National SAFE KIDS Campaign (NSKC) US}

The five year partnership between NSKC and General Motors to promote child passenger safety, costing $\$ 10.6$ million, was announced recently. A packet of materials including press releases and fact sheets on injury in general, motor vehicle occupant injury, the partnership, and some press coverage from USA Today is available. The latter concludes with a challenge: 'Now who will step up to make safety systems truly safe? Who will help parents protect their kids?' (AM).

\section{State bike helmet legislation}

Also from the NSKC comes a brochure summarizing the current status of bike helmet legislation on a state-by-state basis. Fifteen states have enacted such laws and 10 others are in the process of doing so. (Editor's note: what struck me is that in only about one half is a regulatory agency identified and only in New York is that agency the Department of Public Health. Most distressing about this small step in the right direction is that only nine states have fines for non-compliance, the maximum being $\$ 50$ ) (AM)

\section{Fire and halloween safety tips}

Material for selected magazine editors and writers has been assembled by NSKC in anticipation of National Fire Prevention Week 1996 (October 6-12). One focal point is testing smoke detectors; another is eliminating hazards such as matches, lighters, etc. A third is planning and practicing escape routes, and the last is teaching children fire safety. Halloween, at the end of October, has been characterized by Heather Paul as 'one of the most dangerous nights of the year for young children'. Accordingly, NSKC cautions about falls, pedestrian injuries, and burns (AM)

\section{New Zealand Injury Control Bulletin}

The guest editorial in the summer 1995 issue by Reena Kokotailo includes some perspectives on injury prevention in New Zealand; an examination of whether buses should have seat belts by John Langley; a review of some of the child safety work of the Plunket Society (to which Katherine Harvey and Sue Campbell are advisors)

\section{Injury Prevention Research Centre} (New Zealand)

From Auckland, and Robin Norton, comes a copy of the centre's annual report and publication list. With apparently generous support of the Health Research Council, the Accident Rehabilitation and Compensation Insurance Corporation, and the Northern Regional Health Authority, the centre has become a model for many world-wide. The many investigator initiated studies described, arising from this still young (five year old centre, are generally superb. They include the now famous Auckland Child Pedestrian Injury Study, barriers to child restraint use, INSECT (International Study of the Exposure of Children to Traffic), a number of projects on violence including youth suicide prevention and youth risk taking, several dealing with firearms, and, importantly, several that evaluate community interventions. The publications list is too lengthy to summarize: suffice to say that I counted over 30 dealing with child pedestrian injuries alone. In total, I estimated well over 50 of pertinence to child and adolescent injury prevention. Readers are urged to request copies to convince themselves of how much valuable work can be done with adequate support. Further details: Ms C Leonard, Information and Resource Unit Manager, IPRC, University of Auckland, Private Bag 92019, Auckland, New Zealand.
Injury Prevention Research Unit (New Zealand)

In case anyone is confused, the answer is 'yes' - a small country like New Zealand does have not one, but two outstanding injury prevention research groups (with almost identical names!). This one, the unit based at the University of Otago under the leadership of John Langley and David Chalmers, has an equally awesome annual report for 1995 . It continues to be supported mainly by the Accident Rehabilitation and Compensation Insurance Corporation and the Health Research Council and has been approved for a further three years. Of note is the fact that the report includes 35 papers published in peer reviewed journals. Much effort also goes into the production of fact sheets and its new home page on the WWW. Highlights include: the Christchurch Retail Shop Survey (published in Injury Prevention, 1996; 2: 41-3) work on the graduated licensing system, motorcycle injuries, a major study on rugby injuries, playground safety, trampoline and other sports injuries, farm injuries, a focus on international injury, firearms, and injury surveillance. (Further details: IPRU, University of Otago, PO Box 913, Dunedin, New Zealand.)

\section{SAFE KIDS Canada}

This programme recently persuaded Homemaker's Magazine, with its huge readership, to include a section prepared entirely by staff member Jane Rogers. The section, 'Safe Kids are no accident: 40 ways to keep your kids safe this summer' was published under Rogers' byline, and included a description of SAFE KIDS, alongside tips about car, bicycle, playground safety, and scald prevention.

'Think, think again'

This is the catchy slogan being used by SAFE KIDS in Edmonton (Alberta) as part of their campaign to improve child seat restraint use. The full slogan is: 'THINK the kids are buckled up right? THINK AGAIN' (see poster). The project is a combination of education and enforcement, based on a zero tolerance philosophy. Drivers receive a ticket for each child not correctly restrained. Among the options for ticketed drivers is a 45 minute educational session at the local health unit (Joanne Vincenten, Director, SAFE KIDS, Edmonton).

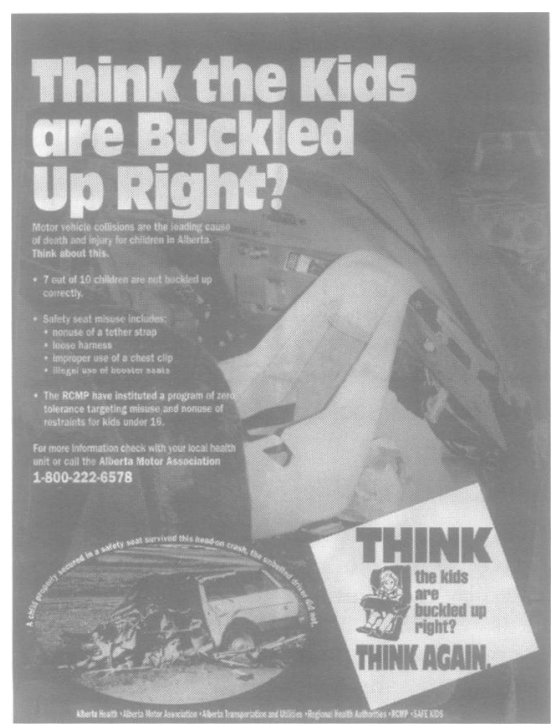


Parent awareness and attitudes survey

From the Alberta SAFE KIDS Campaign, report of a telephone interview survey with 276 parents of children under age 15 . Surprisingly, perhaps, 'accidents' were viewed as the most worrisome risk to children - named by $44 \%$ of respondents. Altogether $25 \%$ reported their children had an injury requiring medical attention within the past year but only about one half of these parents thought the injury could be prevented. More than $80 \%$ of parents favoured bicycle helmet legislation for children (Joanne Vincenten, Edmonton; Carol Beringer, Alberta).

\section{Fact sheets from SAFE KIDS Alberta}

An excellent set of fact sheets from Alberta SAFE KIDS Campaign are available on the following topics: child safety seats, trampoline related injuries, toy safety, bicycle safety, poisonous plants, home safety checklist, child pedestrian injury, and playground safety. These are well designed, cleverly and concisely written, and make good use of a simple three column, three colour format (JV).

\section{Child Safety News}

The June 1996 issue, edited by Jan Shield, and originated from the Royal Children's Hospital Safety Centre (Flemington Road, Parkville 3052, Victoria, Australia) concentrates heavily on transport issues. Among the more controversial issues excerpted are school bus safety, cost effectiveness of compulsory bicycle helmets, a for and against debate on cycle helmets for children, seatbelt use and income, airbag associated fatal injuries, adult accompaniment and risk of pedestrian injury. If you only have time to read one 'journal digest', this is the one I recommend.

\section{Hazard}

Published by the Victorian Injury Surveillance System (VISS) the March issue has an article on 'second generation injury surveillance' - the move to electronic methods of data collection and entry. In the lead article, Watt and Ozanne-Smith state that surveillance data collection is required at three levels: statewide, using a national minimum dataset, comprising level I; a smaller number of hospitals providing more variables information at greater depth (like the current VISS paper based system), comprising level II; and level III, including both of the former alongside additional data for specific injuries, activities, locations, and product types obtained by follow up telephone calls. This issue of Hazard also includes an interesting report on dog bites: nearly one half of the 260 hospital admissions after such bites (100 to be exact) involved 1-4 year old children.

\section{Safe Community News}

An interesting feature in a recent release of Safe Community News, by Josie Livingstone, Safe Castlemilk, a housing estate in Glasgow, Scotland, describes the concern felt at the prospect of World Health Organization Safe Community accreditation - that people might become complacent and the 'we would be over-reaching ourselves' in maintaining the standards set. Nevertheless, Livingstone reports that they 'found the accreditation process empowering'. She adds, 'For Safe Community accreditation to be more influential, community safety needs to be placed more in the mainstream ... [it needs] the same prominence and political backing as Healthy Cities'.
Morbidity and Mortality Weekly Report

This report from the CDC in the US ( 7 June 1996) includes a sobering summary of trends in rates of homicide in the US from 1985 to 1994. Altogether $71 \%$ of the 26009 homicides reported in 1993 were firearm related, and one third of the total involved 15-24 year olds. Also in this issue is a report work related injuries and illnesses associated with child labor in 1993.

\section{Insurance Institute for Highway Safety (IIHS) 'Status Reports'}

The May issue of this IIHS publication has a feature on side impact airbags, predicting that they will 'be in lots of cars very soon'. It lists the manufacturers and models in which they intend to introduce these devices as standard equipment. Another feature deals with the poor enforcement of minimum purchasing age laws for alcohol in the US (Public Health Reports 110:4). Despite this, the report of a survey (Public Attitude Monitor 1995) shows strong support for zero tolerance laws and graduated licensing programs, as well as night time driving curfew laws, for those under 18 years. In a separate study by AF Williams $e t$ al, comparing belt use rate by high school students in 1980 with 1995, it appears use rates have increased but still remain too low, especially among teenage passengers. Mos intriguing is the wide variation in driver belt use rates - from 36 to $91 \%$ depending on the school surveyed. Finally, as should have been expected, after federal maximum speed limits were abolished, drivers are going faster and breaking the new speed limits on urban freeways.

\section{LETTERS TO THE EDITOR}

Third International Conference on Injury Prevention and Control

EDITOR,-The various comments concerning the Third International Conference on Injury Prevention and Control scattered throughout the June 1996 edition of Injury Prevention are appreciated by at least one organiser. While I am pleased that the hospitality aspects of the conference were considered worth the expense of attending a meeting so far away, my purpose in writing to you is to respond to comments about the program and to suggest a new paradigm for thinking about the conferences.

One of my most interesting tasks was to triage all abstracts for review. More than most, I was able to see the broad spectrum of the submitted abstracts. As I read, I saw our intentions to schedule only excellent and innovative papers come falling around our ears. The reason? A large proportion of submitted papers consisted of injury incidence surveys. Many had intervention recommendations bearing no relation to the actual study, simply tacked onto the end. Others were program descriptive papers, many without rigorous evaluation.

While our conference objective was clearly to encourage interdisciplinary understanding, we also wished to ensure the conference series continued to develop scientific rigour. In addition we acknowledged that program personnel at the coal face of injury prevention action are often poorly resourced and isolated; factors often resulting in less than optimal program evaluation. In the end fiscal pragmatism won out - we found a place in the program for all authors in the most creative way we could.

The question needs to be asked once again 'What do we want from international conferences?' We know that health administrators look to conferences for evidence of 'what works'. They want to take advantage of work undertaken by others in order to transfer that knowledge into their strategic plans. While this makes pragmatic sense, it is also illogical. Comments by Forjuoh and Zwi, ${ }^{12}$ highlighting problems concerning the transferability of technology and prevention mechanisms from industrialised to low and middle income countries, point to the pitfalls of such pragmatism. There are similar difficulties involved in such transference between industrialised high income countries, simply because the political and cultural differences are great. We need skills to take injury control principles and apply them to our own political and cultural environments. It may be that the notion of 'what works?' is too simplistic a question to ask.

That being the case, what is it we should expect to get from international conferences? An occasion for debate? Professional training? Learning new skills? New ideas? For most of us all the above apply. The degree to which our expectations of future meetings are met will relate directly to the commitment of the injury prevention community to assisting the development of rigour, and ensuring the establishment of realistic goals in program planning and evaluation, together with commitment to the professional development of new players in the field.

The international injury prevention comunity will reap what it sows. It seems that many health administrators are relucant to invest in sound evaluation of the injury prevention program they fund, and the result is beginning to show. We simply canno continue to expect to benefit from the contribution of others without making a substantial contribution of our own. In addition, we can't expect to receive cutting edge evidence from short term programs run on a shoe string budget.

The Melbourne conference experienced degrees of cooperation from session cont ributors. One North American delegate filled out his program by agreeing to present the abstracts submitted by his colleagues who found they couldn't attend at the last minute. He must have been exhausted by the end of the conference. His commitment to the work of colleagues and to the integrity of the conferences was something I will not forget. He was one of many. At the same time, while the meeting was attended by almost one thousand delegates, I was disappointed to see inexperienced researchers and program personnel presenting their papers to almost empty rooms. From where can they expect to receive helpful feedback on their research/ program methods if not from those who have gone before? (Maybe it said more about the weather and tourism opportunities in Melbourne!)

I suggest that a change of mindset is required. If experienced practitioners focused more on what they could contribute to the conference, rather than what they could get out of it, we may see rapid development reflected in the conference program. Contributions of such kind should be honoured. Maybe future conference organisers could consider ways in which this could be achieved. 